\title{
“... Dar esse salto do vivido para o escrito, isso é a poesia..."
}

\author{
Entrevista a \\ Gastão Cruz
}

Carla Miguelote
(Universidade Federal Fluminense)

CARLA MIGUELOTE: Em ensaio de 1984 sobre seu livro O pianista, Luís Miguel Nava comenta a forma discreta com que a crítica portuguesa vinha se referindo à sua poesia, considerada como "difícil". No ano seguinte, em 1985, esse mesmo livro ganhou o Prémio PEN Clube de Poesia. Dentre os seus seis livros inéditos publicados a partir de então, quatro foram também premiados. A que você atribui essa mudança do posicionamento da crítica em relação à sua obra?

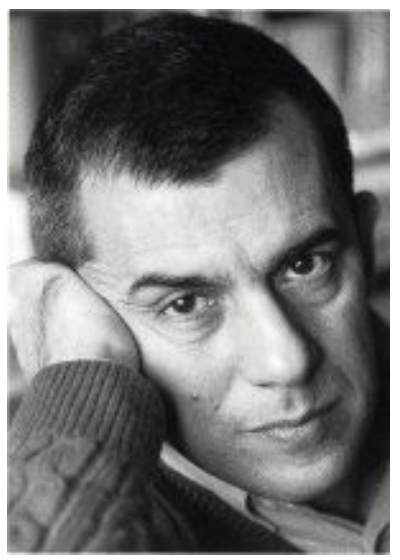

GASTÃO CRUZ: Os prêmios têm um significado muito relativo. Não há que dar demasiada importância. Jorge de Sena queixava-se muito de não ter recebido prêmios. E não é por isso que deixa de ser o Jorge de Sena. O Herberto Helder, por sua vez, recusa os prêmios. Eu penso que, em relação à minha poesia, criou-se um pouco, muito cedo, esse quase mito de que é uma poesia difícil, um bocado abstrata. O que eu não acho que seja verdade. Mas acho que as pessoas têm pouca disponibilidade para ler as coisas com atenção e então preferem coisas que tenham uma leitura mais direta e mais imediata e que, portanto, são mais rápidas de ler. Penso que tenho sido um pouco afetado por isso, sobretudo a partir dos anos 70, em que se começou a insistir muito num suposto "regresso ao real", a uma poesia do cotidiano, como se a poesia dos anos 60 não tivesse nada a ver com o real, o que é uma coisa completamente falsa. Porque os principais poetas dos anos 60, Luiza Neto Jorge, Fiama, eu próprio, e outros, como Armando Silva Carvalho, Ruy Belo, são todos poetas que dão atenção ao 
real, só que, mais ligados talvez aos pressupostos da poesia moderna, tinham uma preocupação em valorizar a linguagem do poema, valorizar as imagens, as metáforas, procurar um grau de inovação maior. Mas eu acho que as pessoas, sobretudo os críticos de jornais, estão sempre procurando o que lhes parece que seja a última moda. E a última moda, até há pouco tempo, era essa poesia mais ligada ao cotidiano, um pouco na linha de uma poesia que se faz, ou fez, em Espanha e que foi chamada poesía de la experiencia - uma poesia em que o poeta fala do café, do bar, da taberna, do centro comercial. Não é a poesia que me interessa mais. Para mim a poesia é, acima de tudo, um trabalho sobre a linguagem, mesmo que, inevitavelmente, ela também fale do mundo que nos rodeia, do real, das nossas vidas.

CM: Se dividirmos os poetas em dois grandes grupos, o dos inspirados e o dos oficinais, o mais apropriado, parece, seria situá-lo dentro do segundo grupo. Entretanto, seguindo as pistas dos primeiros versos do "Inútil poema de amor" - "Mais uma vez a madrugada passa / ou já mesmo a manhã entre os meus braços / e é em decassílabos que vem / a luz muda do dia [...]"-, perguntamonos se aquilo que transparece como resultado de um longo esforço oficinal não seria também fruto de inspiração imediata.

GC: Eu acho que não pode haver uma separação entre inspiração e oficina. Sobre o meu último livro, o crítico Pedro Mexia, que escreve n’O Público, dizia que a minha poesia era cada vez mais uma poesia clássica. Talvez porque há uns ecos de Camões, mas sempre houve, desde Outro nome, ou mesmo antes. Eu tive uma formação inicial muito centrada no soneto, na utilização do decassílabo. Comecei, na adolescência, a fazer sonetos, obedecendo à métrica. Essa formação acaba por marcar um pouco. Alguns poetas hoje nem sabem contar as sílabas. E eu acho que não há nenhum grande poeta que não seja um grande artesão da poesia. Nos clássicos, isso é

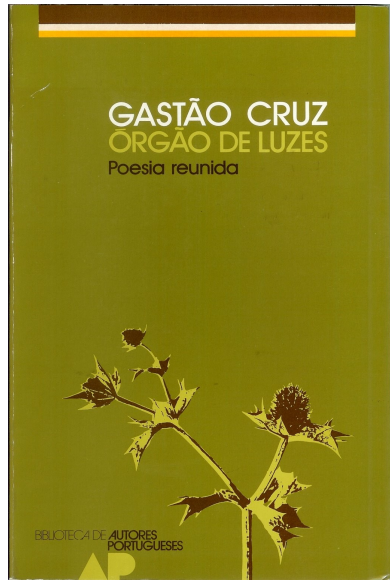
evidentíssimo. A poesia de Camões é uma coisa construidíssima, trabalhadíssima. É inspiração? É artesanato? É as duas coisas. Os Lusíadas, fazer aquilo sem uma técnica extraordinária seria impossível. Mas também na lírica, nas odes, nas elegias, tudo é tão bem trabalhado, tão bem feito... Mesmo depois, nos poetas do século XIX. Baudelaire era um artesão extraordinário, tal como, por exemplo, Mallarmé, ou, em Portugal, Cesário Verde. É claro que o modernismo desmanchou um pouco tudo isso e introduziu o verso livre. Mas mesmo os melhores poemas de Álvaro de Campos, "Ode marítima", "Tabacaria", não é possível escrever aqueles poemas sem uma extraordinária técnica do verso. Quando digo que a manhã vem em decassílabos, é um pouco a idéia de que a manhã só é manhã na poesia quando se transforma em linguagem poética. Esse poema, por exemplo, é um poema que, na verdade, se refere a um momento que tem um conteúdo sentimental na minha vida, mas isso não tem importância nenhuma. Esse conteúdo sentimental podia não ter dado poema nenhum. Portanto automaticamente há uma seleção que tem que ver com o que nós achamos que é alguma qualidade do texto, alguma força e intensidade que conseguimos dar às palavras, essa 
densidade de que fala a Sophia: "o verso é denso, tenso como um arco, exactamente dito, porque os dias foram densos, tensos como arcos, exactamente vividos". A densidade e a tensão do verso são de algum modo função da intensidade da nossa própria vida, da intensidade com que vivemos certos momentos. Agora, dar esse salto do vivido para o escrito, isso é a poesia.

CM: O poema "Em tempo alheio", de Rua de Portugal (2002) tem a seguinte epígrafe buscada em Carlos Drummond de Andrade - "Peço desculpa se ser / o sobrevivente". Isto nos remete a um poema anterior: "Era depois da morte Herberto Helder", em que já se falava de sobreviventes (1984). No prefácio de Poemas Reunidos, você conta que o poema refere um jantar, em Lisboa, na década de 70, que reuniu Herberto Helder, Ruy Belo, Carlos de Oliveira, Jorge de Sena e você.

GC: Foi uma daquelas vezes em que Jorge de Sena, que estava nos Estados Unidos, veio a Portugal, e nós, os outros poetas, oferecemos esse jantar. Passados uns anos, eu dei-me conta de que, dos cinco, já só havia dois. À medida que o tempo avança, desaparecem mais pessoas à nossa roda. E, portanto, nós começamos a sentirmo-nos realmente sobreviventes.

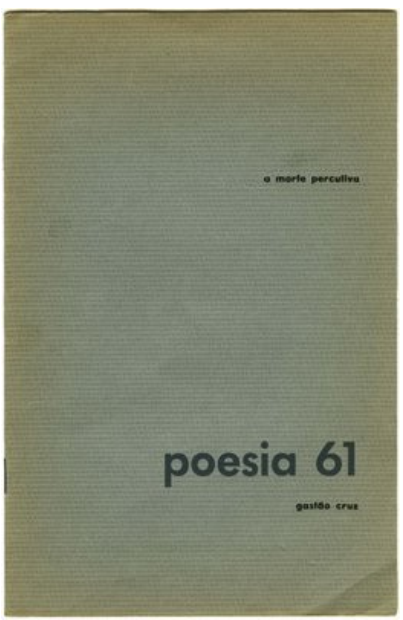

CM: $\mathrm{Na}$ ocasião de "Era depois da morte Herberto Helder", já haviam morrido Carlos de Oliveira, Ruy Belo e Jorge de Sena. Entre esse poema e "Em tempo alheio", morreram Luiza Neto Jorge e Luís Miguel Nava. De lá pra cá, faleceram também Eugênio de Andrade e Fiama Hasse Pais Brandão. Além de todos eles terem sido seus amigos, também eram poetas que compartilhavam uma concepção de poesia que você lamenta estar sendo obliterada por muitos poetas contemporâneos. Você sente estar vivendo num tempo alheio?

GC: É evidente que eu não quero assumir aquele papel das pessoas que dizem "no meu tempo é que era bom e agora é tudo mau". O que eu penso é que os valores em que eu acredito são valores que têm certa perenidade e são valores em que acreditavam as pessoas com quem eu tinha muitas afinidades e muitas opiniões coincidentes, como Luís Miguel Nava, Ruy Belo, Carlos de Oliveira. Penso que esses valores não acabaram, não se esgotaram, porque são os da poesia de sempre. Acho que Camões ou Cesário Verde certamente não teriam valores diferentes desses mesmos, os que estão na base duma alta intensidade do texto. Felizmente alguns desses poetas de quem me sinto mais próximo ainda estão vivos: António Ramos Rosa, Herberto Helder. Mas continuam a escrever e a publicar outros importantes poetas que começaram igualmente nos anos 50: Fernando Echevarría, Fernando Guimarães, Pedro Tamen. E há gente mais nova com quem tenho profundas afinidades. Luís Quintais é um poeta com grande qualidade e importância, revelado em 1995. O século XX português foi poeticamente muito forte. Nas novas gerações não creio que haja, por enquanto, em número 
equivalente, poetas daquele mesmo nível. Recentemente houve uma relativa valorização de uma poesia autointitulada "sem qualidades", de um pequeno grupo liderado por Manuel de Freitas. É um tipo de poesia que me interessa pouco, embora reconheça que existe uma certa qualidade em alguns desses poetas. Mas o conceito de real é neles, por vezes, muito restrito e simplificado. Tem-se, algumas vezes, pegado no célebre poema em prosa de Baudelaire sobre o poeta que perdeu a aura, mas acho que não o têm sabido ler, porque aquele texto é quase uma brincadeira, a aura do poeta cai na lama e ele fica

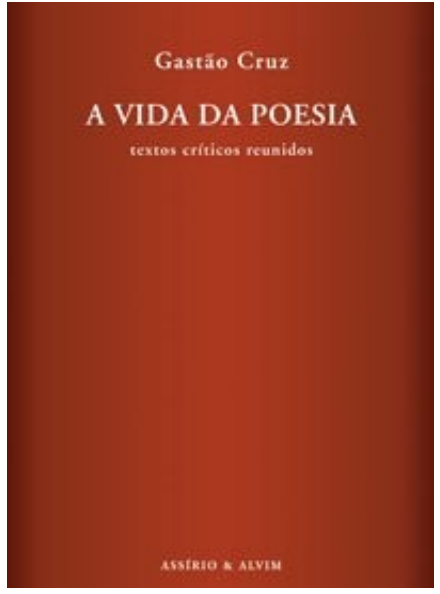
sem carisma nem brilho. Eu prefiro falar (como faço no prefácio do meu livro recente de "textos críticos reunidos", A Vida da Poesia) dos poetas dos quais irradiava uma luz, aí também não separando o autor da pessoa. Não quer dizer que não possa ter havido grandes escritores que fossem, pessoalmente, desinteressantes. Mas os poetas que conheci e admirei, todos tinham um brilho e uma intensidade como pessoas. Tive essa sorte, talvez. Mas não quero deixar de assinalar que já surgiram outras tendências no panorama da poesia portuguesa mais jovem: poetas que procuram novos rumos, empenhados na criação de linguagens poéticas autónomas, de elaboração mais inventiva, e afastando-se do mero registro direto das coisas banais do dia-a-dia. Entre outros nomes, poderei citar os de Joel Henriques, Daniel Jonas ou Miguel-Manso, e referir a nova revista criatura, onde se manifesta a vontade de percorrer caminhos diferentes. 